\title{
APLICAÇÃO DA CONTABILIDADE AMBIENTAL NA INDÚSTRIA MADEIREIRA
}

\author{
Valdiva Rossato de Souza \\ Professora Ms. do Depto. de Ciências Contábeis \\ da Faculdade de Ciências Jurídicas, Gerenciais e Educação - UNIC-Sinop - MT \\ E-mail:valdiva@terra.com.br \\ Maisa de Souza Ribeiro \\ Professora Doutora do Depto. de Ciências Contábeis \\ da FEA-USP - Campus Ribeirão Preto - SP \\ E-mail: maisorib@usp.br
}

\section{RESUMO}

O presente trabalho teve como objetivo o estudo da interação da indústria madeireira localizada na Amazônia mato-grossense com o meio ambiente. Trabalhou-se com a hipótese de que a Contabilidade Ambiental pode ser um agente condutor de informações necessárias à identificação de alternativas para avaliação de investimentos e passivos ambientais na indústria madeireira, de forma a subsidiar o processo de tomada de decisões dos gestores. Para tanto, resgataram-se os principais aspectos sócio-econômicos voltados ao meio ambiente, bem como algumas contribuições científicas que permeiam a Contabilidade Ambiental. O estudo de caso permitiu analisar os principais aspectos sócio-econômico-ambientais que envolvem a empresa, na qual detectou-se que não são ponderadas inúmeras variáveis de desenvolvimento estratégico, fundamentais ao planejamento, controle e tomada de decisões. Identificou-se a necessidade de investimentos ambientais no processo produtivo para o reaproveitamento dos resíduos sólidos da madeira, salientando-se que a realização de tais investimentos deve ser precedida da observação de alguns aspectos relevantes para identificar os recursos consumidos e, para apropriação dos custos ambientais que deverão ser alocados aos investimentos.

Palavras-Chave: Contabilidade Ambiental; Indústria Madeireira; Impactos Ambientais.

\section{ABSTRACT}

This research aimed to study the interaction between the lumber industry located in the Mato Grosso part of Amazonia and the environment. We worked with the hypothesis that Environmental Accounting may produce the necessary information to identify alternatives for evaluating investments and environmental expenses in the lumber industry, so as to support the management decision-making process. Therefore, the main socioeconomic aspects concerning environment were recovered, as well as some scientific contributions that characterize Environmental Accounting. The case study allowed us to analyze the main social, economic and environmental aspects involving the company, discovering that countless strategic development variables are not considered, which are essential for planning, control and decision making. We identified the need for environmental investments in the production process for the reutilization of solid wood waste, pointing out that the accomplishment of such investments must be preceded by the observation of some relevant aspects, in order to identify the consumed resources and adjust the environmental costs, which should be allocated to the investiments.

Keywords: Environmental Accounting; Lumber Industry; Environmental Impact. 


\section{INTRODUÇÃO}

O comércio internacional tem exercido fortes pressões para que os produtos oriundos de florestas nativas atendam aos princípios estabelecidos por normas ambientais, para que possuam maior grau de qualidade e se enquadrem em regras préestabelecidas de desenvolvimento sustentável.

Nesse contexto, deve-se questionar se a forma como as empresas situadas na Amazônia matogrossense, que atuam no setor madeireiro, vêm desenvolvendo suas atividades atendendo às especificações relativas ao meio ambiente, em nível nacional e internacional, tendo em conta que possuem as florestas nativas como base de seu funcionamento e objetivam atuação em mercados globalizados.

No estudo da interação da empresa com o meio ambiente é fundamental a identificação e a mensuração dos impactos ecológicos para auxiliar o processo de gerenciamento ambiental.

A Contabilidade Ambiental surge como uma vertente da Contabilidade Social e tem como objetivo gerar informações que envolvam a interação da empresa com o meio ambiente, e que sejam úteis para a tomada de decisão dos usuários internos e externos. Enquanto veículo de divulgação das informações ambientais, pode oferecer ferramentas necessárias ao controle e divulgação do processo de gestão ambiental implantado pelas empresas, de acordo com os objetivos fixados.

\section{OBJETIVOS}

Desenvolver um estudo para detectar o nível de interação da indústria madeireira localizada na Amazônia mato-grossense com o meio ambiente. Para tanto, será explanado o relacionamento entre as questões ambientais e as informações fornecidas pela Contabilidade, por meio de conceitos fundamentados na literatura existente. Espera-se, a partir disto, evidenciar a aplicabilidade da Contabilidade para o entendimento e controle dos gastos ambientais.

\section{HIPÓTESE}

A Contabilidade Ambiental pode ser um agente condutor de informações necessárias à identificação de alternativas para avaliação de investimentos ambientais na indústria madeireira, de forma a subsidiar o processo de tomada de decisões dos gestores.

\section{PROCEDIMENTOS METODOLÓGICOS}

Para a concretização deste estudo, serão utilizadas como técnicas de trabalho a pesquisa bibliográfica, com análises de contribuições científicas existentes sobre a Contabilidade Ambiental e a empírica, que será desenvolvida com a realização de um estudo de caso em uma indústria madeireira, localizada na Amazônia mato-grossense, que se constitui em Sociedade Anônima com atuação nos mercados interno e externo.

Após levantamento dos dados, serão analisadas as informações e, em seguida, será verificado qual o procedimento adotado pela empresa pesquisada em relação às questões ambientais ou, na ausência deste, quais as alternativas existentes, em conformidade com as orientações científicas pertinentes à aplicabilidade da Contabilidade Ambiental.

\section{REFERENCIAL TEÓRICO}

A Contabilidade é uma ciência que existe desde o princípio da civilização, desenvolvendo-se muito lentamente ao longo dos séculos e atingindo, em torno do século $\mathrm{XV}$, um nível de desenvolvimento acentuado, sendo este período conhecido como "a fase pré-científica da contabilidade". Estas constatações são verificadas em diversas obras, dentre as quais destacam-se as de Hendriksen \& Van Breda (1999) e ludícibus (1997).

Os referidos autores apresentam minuciosos estudos sobre a evolução da contabilidade, listando os estágios de sua evolução, em paralelo ao desenvolvimento econômico mundial, objetivando, primordialmente, atender às necessidades informacionais de seus usuários, e observando aspectos quantitativos e qualitativos das informações fornecidas ao processo de tomada de decisões econômicas, em cada fase da história.

A Contabilidade pode ser conceituada, segundo ludícibus (1997:26), como "o método de identificar, mensurar e comunicar informação econômica, financeira, física e social, a fim de permitir 
decisões e julgamentos adequados por parte dos usuários da informação".

A contabilidade é considerada, atualmente, um sistema de informações que tem como objetivo auxiliar o gerenciamento das entidades, observando aspectos internos e externos, de forma que estas possam garantir sua continuidade. Assim, ludícibus \& Marion (1999:53), explicam que "o objetivo da contabilidade pode ser estabelecido como sendo o de fornecer informação estruturada de natureza econômica, financeira e, substancialmente, física, de produtividade e social, aos usuários internos e externos à entidade objeto da Contabilidade".

\subsection{Contabilidade Ambiental}

De acordo com Ribeiro (1992:56), as questões ambientais devem ser "alvos de preocupações específicas da contabilidade", podendo assim contribuir para a conciliação de um "desenvolvimento econômico sustentável" de acordo com as especificações estabelecidas por entidades governamentais e nãogovernamentais nacionais e internacionais.

Têm aumentado, consideravelmente, nos últimos anos, as discussões sobre qual a melhor forma para que as empresas conciliem seus processos produtivos com questões ambientais, existindo grande conscientização por parte das principais instituições, de que a preservação do meio ambiente é fator determinante para a continuidade e sobrevivência empresariais.

A Contabilidade assume, diante dessa contextualização, papel fundamental de subsídio a todos os agentes envolvidos no processo. Esta deve auxiliar os administradores no que tange ao gerenciamento empresarial das relações com o meio ambiente, por ser considerada, atualmente, uma das principais ferramentas de gestão de negócios. Cabe a ela a elaboração e fornecimento de informações aos usuários internos e externos sobre eventos ambientais que causam modificações na situação patrimonial das entidades.

As informações de caráter ambiental a serem divulgadas pela Contabilidade, segundo Martins \& De Luca (1994:25),

[...] vão desde os investimentos realizados, seja em nível de aquisição de bens permanentes de proteção a danos ecológicos, de despesas de manutenção ou correção de efeitos ambientais do exercício em curso, de obrigações contraídas em prol do meio ambiente, e até de medidas físicas, quantitativas e qualitativas, empreendidas para sua recuperação e preservação.

A seguir, descrever-se-ão alguns conceitos básicos da Contabilidade tradicional adaptados para a Contabilidade Ambiental.

\subsubsection{Ativos Ambientais}

Algumas das concepções definidas para Ativo Ambiental são relacionadas a seguir.

Conforme a United Nations Conference on Trade and Development - Unctad (1998:4-5) ativos ambientais são gastos capitalizados e amortizados nos períodos presente e futuro, que satisfazem aos critérios de reconhecimento como um ativo, o que ocorrerá quando houver controle de recursos aplicados por uma empresa como resultado de eventos passados e dos quais se espera benefícios econômicos futuros.

Ribeiro (1998:57) corrobora tal definição afirmando que:

[...] ativos ambientais são recursos econômicos controlados por uma entidade, como resultado de transações ou eventos passados, dos quais se espera obter benefícios econômicos futuros, e que tenham por finalidade o controle, preservação e recuperação do meio ambiente.

Na concepção de Martins \& De Luca (1994:26), "os ativos ambientais são todos os bens da empresa que visam à preservação, proteção e recuperação ambiental..."

Com tais ensinamentos, percebe-se que todos os ativos relacionados ao meio ambiente podem ser contabilizados separadamente, de forma a evidenciar à sociedade, quais os atos que a empresa vem praticando, no sentido de observar as normatizações internacionais sobre tais práticas.

Desta forma, Martins \& De Luca (1994:26) ressaltam que os ativos ambientais devem ser segregados à parte no Balanço Patrimonial, de forma a 
melhorar a avaliação dos usuários sobre as ações ambientais da empresa, da seguinte forma:

- [...] estoques - insumos em almoxarifado necessários à produção para eliminar, reduzir ou controlar os níveis de emissão de poluentes, materiais para recuperação de ambientes, etc.;

- imobilizado - investimentos realizados na aquisição de itens (máquinas, equipamentos, instalações, etc.) que viabilizem a redução de resíduos poluentes durante o processo de obtenção de receitas e cuja vida útil se prolongue além do término do exercício social;

diferido - investimentos em pesquisa e desenvolvimento de tecnologia no longo prazo, quando estes puderem ser claramente relacionados com receitas futuras de períodos específicos.

\subsubsection{Passivos Ambientais}

Conforme entendimento da Unctad (1998:5) o passivo pode ser constituído da obrigação legal, contratual ou justa. As definições são interessantes, principalmente, porque incluem, claramente, a questão ambiental. Segundo a entidade, a obrigação legal é determinada com base estatutária ou em legislação. A obrigação construtiva é decorrente de fatos específicos em que a responsabilidade da companhia fica evidente a ponto de não se poder negar sua assunção, como no caso de um vazamento de resíduo tóxico. A obrigação justa é uma forma de obrigação construtiva, pois é baseada em considerações éticas e morais.

Segundo Ribeiro (1998:70),

[...] os passivos ambientais devem ser constituídos pela expectativa de sacrifícios futuros impostos por legislações e regulamentações ambientais, como taxas, contribuições, multas e penalidades por infrações legais e, ainda, em decorrência de ressarcimento a terceiros por danos provocados, estimativa de gastos para recuperação e restaurações de áreas degradadas, seja por iniciativa própria, seja exigido por lei ou terceiros. Enfim, todos os compromissos que impliquem o provável consumo de recursos futuros para fazer face às obrigações decorrentes de questões ambientais.

Para Martins \& De Luca (1994:27), [...] os passivos ambientais referem-se a benefícios econômicos que serão sacrificados em função de obrigação contraída perante terceiros para preservação e proteção ao meio ambiente. Têm origem em gastos relacionados ao meio ambiente, que podem constituir-se em despesas do período atual ou anteriores, aquisição de bens permanentes, ou na existência de riscos de esses gastos virem a se efetivar (contingências).

Percebe-se, dessa forma, que a definição de passivos ambientais é decorrente também das utilizadas pela contabilidade tradicionalmente, atribuída, entretanto, ao controle, preservação, recuperação e gastos incorridos especificamente com o meio ambiente.

No que diz respeito à origem dos passivos ambientais, Ribeiro \& Lisboa (2000:11) ressaltam que esta advém de qualquer evento ou transação que reflita a interação da empresa com o meio ecológico, em que sacrifício de recursos econômicos se dará no futuro, a partir, principalmente, dos seguintes eventos:

[...] a) aquisição de ativos para contenção dos impactos ambientais (chaminés, depuradores de águas químicas etc);

b) aquisição de insumos que serão inseridos no processo operacional para que este não produza resíduos tóxicos; c) despesas de manutenção e operação do 'departamento' de gerenciamento ambiental, (inclusive mão-de-obra);

d) gastos para recuperação e tratamento de áreas contaminadas (máquinas, equipamentos, mão-de-obra, insumos em geral etc);

e) pagamento de multas por infrações ambientais;

f) gastos para compensar danos irreversíveis, inclusive os relacionados à tentativa de reduzir o desgaste da imagem da empresa perante a opinião pública, etc. 
Neste sentido, a ONU apud Ribeiro \& Lisboa (2000:11), explica que o passivo ambiental passa a existir, quando:

[...]"a) houver uma obrigação de a entidade prevenir, reduzir ou retificar um dano ambiental, sob a premissa de que a entidade não possui condições para evitar tal obrigação. Esta ausência de condições é definida pelas seguintes situações:

i) existência de uma obrigação legal ou contratual;

ii) política ou intenções da administração, prática do ramo de atividade, ou expectativas públicas; ou

iii) divulgação, por parte da administração, interna ou externamente, de sua decisão de prevenir, reduzir ou retificar o dano ambiental de sua responsabilidade.

b) o valor da exigibilidade pode ser razoavelmente estimado.

Com tais explanações, evidencia-se que diante da existência de ativos ambientais, surge também a figura do passivo ambiental respectivo, tendo em vista que a essência deste é caracterizada pelos gastos gerados para controle e reversão dos impactos causados pelas atividades operacionais ao meio ambiente em que a empresa está inserida, cujos pagamentos ocorrerão no futuro.

Segundo a Price Waterhouse Coopers Auditores (2000:116), a administração das empresas, normalmente, tem tomado a decisão de registrar os passivos ambientais em função de diferentes motivos, tais como:

- [...] descoberta de passivos ambientais por estudos internos;

- quando se conclui pela necessidade de se efetuar remediação do meio ambiente, durante o estudo das alternativas de recuperação e sua viabilidade;

- após o estudo das alternativas de recuperação e sua viabilidade, quando então está definido o método a ser usado para recuperar o meio ambiente;

- quando notificado pelas autoridades;

- à medida que os custos de recuperação incorrem.
A complexidade que envolve a mensuração adequada de passivos ambientais, gira em torno do fato de que, na maioria das vezes, a recuperação do meio ambiente é tarefa que leva anos para ser concluída e, nesse período, ocorrem alterações dos custos inicialmente projetados. Entretanto, este fato não deve inviabilizar o registro das obrigações ambientais, tendo em vista que a omissão de tais valores não estará explicitando a veracidade dos impactos causados pelas organizações à humanidade.

\subsubsection{Contingências}

Outras situações que devem ser observadas pela Contabilidade dizem respeito às contingências. Para a Fipecafi (2000:247), "...contingência é uma situação de risco já existente e que envolve um grau de incerteza quanto à efetiva ocorrência e que, em função de um evento futuro, poderá resultar em ganho ou perda para a empresa".

Ribeiro (1992:107) explica que

[...]a contingência caracteriza-se nos casos em que a responsabilidade da empresa, na consumação do fato gerador, depende da efetivação de um evento futuro, (...). A provisão contábil está preocupada com a expectativa futura de recebimentos e pagamentos no processo de reconhecimento de ativos, passivos, receitas, despesas, ganhos ou perdas.

O que se verifica com tais explanações é que a essência das contingências refere-se à necessidade de estimativas dos valores a serem reconhecidos, sendo que, caso estimativas adequadas não sejam factíveis, os possíveis efeitos sobre a posição patrimonial da entidade deverão ser divulgados, de forma que mostrem a objetividade dos fatos e das evidências que suportam as estimativas para registro contábil ou divulgação em notas explicativas.

\subsubsection{Custos e Despesas Ambientais}

Os custos ambientais, segundo Ribeiro (1998:177) "são representados pelo somatório de todos os custos dos recursos utilizados pelas atividades desenvolvidas com o propósito de controle, preservação e recuperação ambiental". 
Conforme a ONU-Unctad (1998:6) os custos ambientais são os gastos realizados, pagos ou não, para gerenciar, de forma responsável, os impactos ambientais das atividades da empresa, além de outros gastos direcionados para objetivos ambientais e exigidos pelo contexto operacional da companhia. Afirma ainda que os custos ambientais devem ser reconhecidos em confrontação às receitas do período em que são identificados.

Para a U. S. Environmental Protection Agency - EPA (1995:8-11) os custos ambientais devem ser classificados em quatro categorias: "custos convencionais; custos potencialmente ocultos; custos com contingências; custos de imagem e relacionamento".

Os custos convencionais podem incluir aqueles associados aos aspectos ambientais tangíveis dos processos e atividades exercidos pela entidade, tais como os investimentos em equipamentos, matéria-prima, mão-de-obra e materiais indiretos. A utilização de mecanismos de controle para estes custos induz ao aumento de eficiência pela eliminação do desperdício dos recursos.

Os custos potencialmente ocultos podem incluir todos os gastos oriundos de atividades necessárias para que a empresa se enquadre nas normas reguladoras de proteção ambiental ou políticas ambientais da própria organização. Destacam-se os custos com monitoramento ambiental, treinamento de funcionários, relatórios ambientais, dentre outros.

Os custos com contingências podem envolver os gastos aos quais a empresa pode estar sujeita, mas que dependem de outros fatores extrínsecos para a sua efetivação. Incluem-se os custos com regulamentações, multas e penalidades por danos ao meio ambiente, gastos com recuperação de recursos naturais danificados etc.

Os custos de imagem e relacionamento envolvem aqueles necessários para a divulgação do desempenho ambiental da empresa aos acionistas, comunidade e governo. A preocupação da empresa em relação à preservação do meio ambiente pode melhorar ou prejudicar seu relacionamento com terceiros e os impactos podem implicar em custos adicionais ou perdas financeiras por multas ou indenizações.
Com o conhecimento de todas estas categorias de custos ambientais, o sistema de sua gestão estratégica permitirá razoável avaliação dos possíveis riscos ambientais que a empresa esteja assumindo, de forma que sejam conhecidos e analisados pelos dirigentes da companhia, bem como evidenciados aos usuários externos.

Diversos fatores evidenciam que existe, em certos casos, elevado grau de dificuldade por parte das empresas em reconhecer seus gastos ambientais, o que caracteriza a necessidade de serem procedidos estudos de viabilidade, quando da implantação de determinados empreendimentos, de forma a garantir maior nível de confiabilidade às estimativas de custos com recuperação e/ou redução de impactos ambientais.

De acordo com Carvalho \& Ribeiro (2000:5), em 1990 e 1993, o FASB dos Estados Unidos emitiu pronunciamento ressaltando a aplicabilidade e necessidade de contabilização dos custos e passivos ambientais, a partir do conhecimento de sua existência e grau de probabilidade de sua eventual exigibilidade.

Com relação às despesas ambientais, Ribeiro (1998:95) ressalta que devem envolver todos os gastos com gerenciamento ambiental, consumidos no período e incorridos na área administrativa. Assim, podem contemplar gastos relativos a horas de trabalho, bem como seus respectivos encargos sociais e, também, os insumos absorvidos nas seguintes atividades:

- [...] na definição e manutenção de programas e políticas ambientais;

- na seleção e recrutamento de pessoal para o gerenciamento e operação do controle ambiental;

- na compra de insumos e equipamentos antipoluentes;

- no pagamento das compras realizadas para a área ambiental;

- na recuperação dos itens ambientais adquiridos;

- para a estocagem dos insumos utilizados no controle ambiental;

- em treinamentos específicos para a proteção ambiental;

- na auditoria ambiental. 


\section{CARACTERIZAÇÃO DA EMPRESA EM ESTUDO}

\subsection{Aspectos Gerais}

A Compensados Fortes S/A, constituída sob a forma de sociedade por ações de capital fechado, iniciou suas atividades no dia 19 de outubro de 1989 , com sede no Município de Sinop-MT.

Seus objetivos sociais caracterizam-se da seguinte forma:

- Fabricação e comercialização de chapas de madeira compensadas, revestidas ou não com material plástico;

- Beneficiamento de madeiras serradas em aparelhadas;

- Fabricação de portas;

- Comércio atacadista de madeiras em toras, serradas, aparelhadas, beneficiadas e em portas, e

- Exportação de madeiras.

O mercado interno foi o primeiro a ser conquistado e, posteriormente, passou a expandir suas vendas ao mercado externo, onde comercializa atualmente seus produtos em diversos países, dentre os quais destacam-se: Bélgica, E.U.A., Espanha, Inglaterra, Irlanda, Malásia e Indonésia. Entretanto, a empresa enfrenta forte concorrência no mercado externo de empresas localizadas, basicamente, no Japão e Indonésia.

\subsection{Aquisição de Madeira para Industrialização}

Apesar de a empresa possuir reservas florestais nativas, atualmente não as utiliza, sendo a totalidade de sua matéria-prima (madeira) adquirida de terceiros. Neste sentido, as toras são adquiridas em regiões que estão a 270 quilômetros de distância da sede. A empresa consome em seu processo produtivo a média de $39.600 \mathrm{~m}^{3}$ de madeira/ano.

O valor da madeira varia de acordo com a distância em que está localizada, tendo em vista que o frete é pago pela empresa que a adquire.

A mão-de-obra para extração de toras é paga pela empresa compradora, proporcionalmente à quantidade adquirida, em metros cúbicos de madeira.

Desta forma, os itens que compõem o custo de aquisição da madeira, se constituem em custos operacionais para a empresa.

A empresa deve certificar-se de que seus fornecedores de matéria-prima sejam detentores do Selo Verde, já que é uma exigência do mercado internacional, para onde é destinada a grande maioria dos produtos comercializados pela empresa, que está sujeita a custos ambientais de imagem e relacionamento.

Para efeitos deste estudo, não foi procedida a avaliação das condições de extração de madeira dos fornecedores da empresa em questão. Entretanto, vale ressaltar que a mesma deve estar preocupada com a legalidade de sua procedência, pois a qualidade da matéria-prima pode interferir em seu processo produtivo e deposição do produto após uso ou consumo.

\subsection{Apropriação Gerencial dos Custos de Produção}

A empresa utiliza para a apropriação dos custos de seus Produtos Comercializados o Método do Custo Integral. Trata-se de um prolongamento do Custeio por Absorção, onde as despesas com vendas e administrativas são totalmente alocadas aos produtos através de critérios de rateios, conforme planilhas de cálculo do setor responsável.

Ao explanar sobre o referido método, Martins (2000:237) ressalta que "é muito mais provável que uma empresa analise seus custos e suas despesas para verificar se é viável trabalhar com um produto, cujo preço o mercado influencia marcantemente ou mesmo fixa, do que ela determinar o preço em função daqueles custos ou despesas".

Diante disto, o autor citado ressalta que, em uma economia de mercado, este "é o grande responsável pela fixação dos preços". Portanto neste contexto, o tratamento dos custos visa reduzi-los para aumentar o resultado.

\subsection{Caracterização do Processo Produtivo}

O processo produtivo da Compensados Fortes S/ A caracteriza-se pela transformação de toras em chapas de compensados. Para tanto, após a colocação da madeira no pátio da empresa, são seguidas algumas fases no processo, que geram resíduos. $O$ destino destes e suas respectivas destinações, podem ser evidenciados na tabela 1. 
Tabela 1 - Resíduos Sólidos do Processo Produtivo

\begin{tabular}{|c|c|c|c|}
\hline Resíduo & Pontos de Geração & Quantidade & Destino \\
\hline Ponta de toras & Seccionamento & $1.320 \mathrm{~m}^{3}$ & Caldeira \\
\hline Casca de toras & Seccionamento & $1.584 \mathrm{~m}^{3}$ & Forno \\
\hline Roletes & Desfolhamento & $3.168 \mathrm{~m}^{3}$ & Caldeira \\
\hline Lâminas/laminadora & Desfolhamento & $12.672 \mathrm{~m}^{3}$ & Forno \\
\hline Refilo de compensado & Esquadrejamento & $1.900 \mathrm{~m}^{3}$ & Caldeira \\
\hline Lâminas/compensado & Processo Produtivo & $720 \mathrm{~m}^{3}$ & Caldeira \\
\hline Pó da madeira & Lixamento & $720 \mathrm{~m}^{3}$ & Ao solo \\
\hline Pó da serra & Esquadrejamento & $720 \mathrm{~m}^{3}$ & Ao solo \\
\hline Fumaça & Forno & Sem medição & Ao ar \\
\hline Total (exceto a fumaça) & & $22.804 \mathrm{~m}^{3}$ & \\
\hline Reaproveitamento (caldeira) & & $7.108 \mathrm{~m}^{3}$ & Caldeira \\
\hline Queima com geração de fumaça (forno) & & $14.256 \mathrm{~m}^{3}$ & Forno \\
\hline Resíduos ao solo/ar (exceto a fumaça) & & $1.440 \mathrm{~m}^{3}$ & Ao solo \\
\hline
\end{tabular}

Fonte: Diagnóstico ambiental e de processo da Compensados Fortes S/A.

Até a realização do inventário de resíduos sólidos gerados no processo produtivo, de acordo com as especificações da Fema-MT - Fundação Estadual do Meio Ambiente de Mato Grosso -, a empresa não possuía método estatístico para conhecer o percentual de perda da matéria-prima (toras), sendo tal "quebra" (perda) estipulada com base em cálculos mensais, resultantes da confrontação do consumo em toras e da produção final de compensado.

Entretanto, após realização de inventário dos resíduos sólidos com apoio da Fema, é possível conhecer o percentual de perda da madeira no processo produtivo de forma mais aproximada.

Do total da madeira consumida no processo produtivo, $60,36 \%$ é realmente utilizada para comercialização e/ou geração de energia, enquanto que os restantes $39,64 \%$ são transformados em resíduos sem utilização pela indústria, com incorporação aos custos de produção. Tais resíduos são lançados ao solo/ar, em forma de poeira (pó de madeira e de serra); fumaça expelida pelo forno e, cinzas que ficam expostas, a granel, em área da empresa, sem cobertura.

Assim, para a empresa, não basta apenas preocupar-se com a procedência da madeira, sendo também necessários investimentos em seu processo produtivo, objetivando, principalmente, o reaproveitamento, tendo em vista que tais desperdícios são caracterizados como perdas, as quais são rateadas à produção, quando de sua comercialização.

Tal "quebra", na atual situação, caracteriza-se como custos ambientais convencionais para a empresa, tendo em vista a procedência da matéria-prima (madeira), bem como a ausência de investimentos no sentido de reaproveitá-la.

\subsection{Proveniência e Consumo de Água}

Paralelamente ao processo produtivo, a empresa consumiu $31.270 \mathrm{~m}^{3}$ de água proveniente de poço em 2001, para abastecimento da caldeira, lavagem de pisos, equipamentos e veículos, irrigação de toras seccionadas e incorporação ao produto.

O funcionamento das prensas também consome água, gerando vapor, sendo que este não retorna ao processo produtivo, ocasionando um desperdício de aproximadamente $120 \mathrm{~m}^{3}$ de água/ano, o que representa cerca de $0,38 \%$ do total de água consumida.

Tal desperdício, na atual situação, caracteriza-se como custo ambiental convencional para a empresa, tendo em vista a ausência de investimentos no sentido de reaproveitá-lo.

Pelo fato de a água consumida ser proveniente de poço existente nas delimitações da empresa, esta não possui qualquer medida de controle para conhecer os custos financeiros incorridos com a mesma. Entretanto, tais custos poderiam ser conhecidos com a realização de simulação, adotando-se por base a quantidade consumida e o valor cobrado pela empresa fornecedora de água local.

\section{Efluentes Líquidos:}

Com a utilização da água em suas instalações, a empresa gera resina como efluente líquido no processo produtivo. Assim, possui vazão de resina oriunda das 
caldeiras e proveniente de lavagem de pisos e equipamentos (conforme tabela 2), que é armazenada em uma fossa com decantação em três estágios, sendo que, até o momento, a empresa não possui projetos para a implantação de tratamento do referido efluente.

Tabela 2 - Informações sobre Efluentes Líquidos

\begin{tabular}{|c|c|c|c|}
\hline Resíduo & Pontos de Geração & Quantidade & Destino \\
\hline Resina & Caldeiras & $0.200 \mathrm{~m}^{3}$ & Fossa \\
\hline Resina & Lavagem de pisos e equipamentos & $0.500 \mathrm{~m}^{3}$ & Fossa \\
\hline Total & & $0.700 \mathrm{~m}^{3}$ & \\
\hline Reaproveitamento & & $0.000 \mathrm{~m}^{3}$ & \\
\hline Resíduos ao solo & & $0.700 \mathrm{~m}^{3}$ & Ao solo \\
\hline
\end{tabular}

Fonte: Diagnóstico ambiental e de processo da Compensados Fortes S/A.

Por outro lado, a empresa possui a alternativa de tratamento de tais efluentes antes de sua destinação final, através de sistemas de remoção dos resíduos sólidos presentes no efluente, bem como tratamentos biológicos em que os materiais suspensos e dissolvidos seriam degradados por microorganismos.

Cabe ressaltar que, para a implantação de tais sistemas, haverá necessidade de desenvolvimento de projetos que envolverão desde a aquisição de equipamentos até a realização de construções civis para seu funcionamento, bem como o respectivo acompanhamento de profissionais especializados que estarão realizando testes para detectar os resultados em prol da minimização dos impactos. Todas as atividades envolvidas estarão gerando custos ambientais à empresa, os quais devem ser conhecidos e controlados.

Com o exposto neste estudo, percebe-se que cada vez mais as regulamentações em prol do meio ambiente têm aumentado, visando conscientizar as empresas de que o uso de modernas tecnologias de processo e controle ambiental, bem como práticas operacionais voltadas à prevenção de riscos e poluição devem fazer parte de seu funcionamento, de forma a permitir melhor performance ambiental.

Entretanto, para efeitos deste estudo, não serão mensurados os investimentos necessários para o tratamento dos efluentes líquidos da empresa, pois, apesar de importantes, não se caracterizam como os mais relevantes e, também, em função da delimitação do objeto de estudo, o que não isenta a empresa da responsabilidade ambiental em realizá-los.

Diante da necessidade cada vez mais presente de realização de tais investimentos, sua ausência caracteriza-se como passivos ambientais contingenciais que não estão sendo identificados pela empresa até o momento, tendo em vista a existência de exigibilidades legais.

\subsection{Formas de Geração e Consumo de Energia}

Para viabilizar o processo produtivo, a empresa consome, anualmente, $1.046 .704 \mathrm{kw} / \mathrm{h}$ de energia elétrica adquirida de concessionária hidrelétrica responsável pelo abastecimento da região e, ainda, uma média anual de 116.200 litros de óleo diesel para a geração de energia.

A empresa também consumiu, em 2001 , $9.500 \mathrm{~m}^{3}$ de resíduos sólidos de madeira, para queima que viabilizou o funcionamento da caldeira. Este, por sua vez, ocasionou uma economia de custos para a empresa.

Entretanto, a empresa não possui apontamento que identifique o consumo de quilowatts/hora de energia para funcionamento das máquinas, ficando prejudicada a identificação do montante da economia em questão.

\section{Emissões Atmosféricas:}

O consumo de óleo diesel e resíduos de madeira no processo produtivo gera emissões atmosféricas nos pontos que são pelos mesmos abastecidos, como é o caso da empilhadeira e pá carregadeira, que utilizam óleo diesel para seu funcionamento, e da caldeira, que é abastecida por resíduos da madeira.

A empresa, até o momento, não possui estudos sobre tais emissões, como também não 
possui equipamentos especiais de controle/redução de tais emissões instalados nos referidos pontos do processo. Assim, ao optar pela realização de tais investimentos, deverá estar observando seus custos de aquisição/implantação, bem como identificando-os de forma que se caracterizem como custos ambientais da empresa.

Da mesma forma que os efluentes líquidos, não serão mensurados os investimentos necessários para a redução/controle de emissões atmosféricas da empresa em estudo, salientando que sua ausência vem contribuindo para o crescimento do passivo ambiental contingencial da empresa, pela existência de exigibilidades legais em função de tal redução/controle.

\section{ANÁLISE DO ESTUDO DE CASO}

Para uma empresa que exerce a atividade madeireira, os cuidados ambientais devem ser encarados como uma questão de sobrevivência, tendo em vista que a conservação dos recursos naturais, principalmente das florestas, representa sua sustentabilidade e garante sua continuidade.

$\mathrm{Na}$ atividade madeireira, os impactos ambientais são considerados relevantes, pois ocorrem em diversas fases do processo. Entretanto, para o caso da empresa objeto deste estudo, tendo em vista que a totalidade da madeira utilizada em seu processo produtivo é proveniente de matas de terceiros, observa-se que sua maior preocupação deve girar em torno dos resíduos sólidos da madeira, gerados na industrialização de seus produtos.

\subsection{Aquisição de Máquinas}

O mercado fabricante de máquinas e equipamentos para o setor madeireiro tem disponibilizado novas alternativas tecnológicas que visam eliminar, via reaproveitamento, a grande maioria dos resíduos gerados no processo produtivo. Com tais equipamentos, a empresa poderia optar por investir em novas tecnologias que utilizem a grande maioria dos resíduos para a produção de energia, por exemplo.

Atualmente, a empresa utiliza, basicamente, pontas de toras, roletes e refilos de lâminas e compensados para a geração de energia, sendo a serragem totalmente queimada no forno. Há no mercado tecnologias que permitem a reutilização da grande maioria de seus resíduos e eliminação da fumaça que é expelida permanentemente ao ar e, ainda, a empresa poderia tornarse auto-suficiente em produção energética.

Para efeitos deste estudo, realizou-se pesquisa exploratória, via Internet, junto às empresas fornecedoras de máquinas e equipamentos específicos ao setor madeireiro, para detectar a existência de tecnologias que sirvam de opção para a empresa realizar uma reestruturação em seu processo produtivo, objetivando a minimização de seus resíduos sólidos de madeira.

Desta forma, detectou-se que no mercado existem máquinas que eliminam a grande maioria dos resíduos sólidos gerados no processo produtivo e, conseqüentemente, fariam com que a empresa aumentasse seu potencial de produção energética, com o aproveitamento do vapor oriundo da caldeira. Há, também, máquinas que viabilizam a fabricação de subprodutos que possuem demanda nos mercados interno e externo.

De acordo com as especificações da empresa, obteve-se junto a fornecedores do referido produto $^{1}$, projeto para reestruturação do processo produtivo, ressaltando-se que as máquinas, a seguir elencadas, não podem pura e unicamente ser instaladas sem toda uma vistoria prévia de profissionais qualificados, no sentido de verificar a compatibilidade destas com o restante do processo produtivo.

\section{Primeira Alternativa:}

Aquisição de Máquinas para Redução de Resíduos Sólidos

Com a caldeira e a máquina a vapor, que em janeiro de 2003 corresponderia ao valor de $R \$$ $514.610,00$ (quinhentos e quatorze mil, seiscentos e dez reais), a empresa estaria eliminando a grande maioria de seus resíduos gerados no processo produtivo e produzindo energia para suprir toda a sua demanda e, conseqüentemente, tornando-se autosuficiente neste aspecto.

${ }^{1}$ A Benecke Irmãos \& Cia Ltda, através de seu representante comercial, disponibilizou via e-mail projeto solicitado pela pesquisadora para reestruturação do processo produtivo da Compensados Fortes S/A, ressaltando-se que os valores são ilustrativos e têm como objetivo demonstrar a realidade econômica de tais investimentos. 
O secador contínuo, que em janeiro de 2003, corresponderia ao valor de $\mathrm{R} \$ 325.380,00$ (trezentos e vinte e cinco mil, trezentos e oitenta reais), seria compatível com as especificações da caldeira e máquina a vapor, e se faz necessário para otimizar o processo de secagem das lâminas.

A realização de tais investimentos seria caracterizada como investimentos ambientais, tendo em vista que estariam sendo realizados com o principal propósito de minimizar os impactos ambientais ocasionados pela empresa.

Segunda Alternativa:

Aquisição de Máquinas para Fabricação de Subprodutos

A juntadeira selecionadora de lâminas, que em janeiro de 2003, corresponderia ao valor de $\mathrm{R} \$ 485.560,00$ (quatrocentos e oitenta e cinco mil, quinhentos e sessenta reais), apresenta-se como mais uma alternativa para que a empresa reduza seus resíduos, pois, com tal equipamento, a empresa estaria aumentando seu reaproveitamento e, conseqüentemente, reduzindo seus resíduos sólidos. Assim, além de redução de custos, haveria um aumento de produtividade, visto que a empresa estaria diversificando sua produção, com subprodutos que possuem demanda nos mercados interno e externo.

Ressalte-se que tal investimento eliminaria apenas pequena quantidade dos resíduos sólidos de madeira, tendo a empresa que buscar outra alternativa para destinação final aos resíduos remanescentes (principalmente a serragem).

\subsection{Gastos Decorrentes da Decisão de Não Adquirir Novas Máquinas}

\section{Terceira Alternativa:}

Gastos Decorrentes da Decisão de Não Adquirir Novas Máquinas

De acordo com a portaria Conjunta $\mathrm{n}^{\circ} 12$, de 25 de abril de 2002, que estabelece regras e precauções para o uso do fogo nas práticas florestais, a empresa deverá deixar de realizar a queima de resíduos de madeira no forno, pois tal situação causa consideráveis danos ao meio ambiente e à população local, principalmente na "época da seca".
O parque industrial madeireiro em questão localiza-se nas proximidades do perímetro urbano.

Porém, se a empresa optar pela continuidade de tal situação, estará sujeita às sanções penais impostas pela Lei Federal de Proteção Ambiental no 9.605, de 13.02.98, bem como às impostas pela Lei Estadual Complementar $n^{\circ} 38$, de 21.11 .95 , que trata das infrações ambientais.

Entretanto, para que não haja duplicidade de aplicação de penalidades, a Lei Federal estabelece, em seu artigo 76, que "o pagamento de multa imposta pelos Estados, Municípios, Distrito Federal ou Território substitui a multa federal na mesma hipótese de incidência".

Desta forma, o que ocorre atualmente no Estado de Mato Grosso é a aplicabilidade, primeiramente, da Legislação Estadual e, posteriormente, caso haja necessidade, a aplicação da Legislação Federal. Portanto, vale ressaltar que a empresa não está isenta de receber as sanções maiores impostas pela Legislação Federal e que, diante de tal ocorrência, estaria comprometendo a continuidade de seu funcionamento, pois tal penalidade é consideravelmente superior ao seu Patrimônio Líquido.

Para efeitos deste estudo, estarão sendo desconsiderados tais valores, tendo em vista a dificuldade em conhecer seus parâmetros e a grande disparidade entre os limites mínimo e máximo.

No que tange à Legislação Estadual, a empresa deve observar os limites máximos das sanções impostas em tal situação, em observação ao Princípio da Prudência. Assim, a mesma estaria sendo autuada em 1.000 (mil) UPF-MT - Unidade Padrão Fiscal de Mato Grosso -, que em janeiro de $2003^{2}$, corresponderia ao valor equivalente de $\mathrm{R} \$ 20.770,00$ (vinte mil setecentos e setenta reais).

Deve-se observar, também, que a legislação especifica, para os casos de reincidência, autuação correspondente ao dobro da anteriormente imposta, ou seja, o valor equivalente a $\mathrm{R} \$ 41.540,00$ (quarenta e um mil quinhentos e quarenta reais).

Entretanto, tendo em vista que o funcionamento do forno é contínuo, a legislação estadual também prevê a aplicação de multa diária e progressiva sobre os valores originalmente estabelecidos, podendo estender-se pelo período de até 30 (trinta) dias,

${ }^{2}$ O Valor da UPF-MT em janeiro de 2003 corresponde a R\$ 20,77, de acordo com a Portaria 01/03, disponível em <www.sefaz.mt.gov.br>, acesso em: 14.01 .2003$. 
contados da data de sua imposição, o que acarretaria um montante de $\mathrm{R} \$ 623.100,00$ (seiscentos e vinte e três mil e cem reais), em apenas uma autuação. Ressalte-se que, após o decurso de tal prazo, havendo continuidade da infração, o ciclo de autuações poderá ser retomado.

\subsection{Análise Contábil dos Impactos Ambientais}

Aplicação da Primeira Alternativa:

Aquisição de Máquinas para Redução de Resíduos Sólidos

A primeira alternativa consiste na aquisição de máquinas (caldeira, máquina a vapor e secador contínuo) que consumirão a grande maioria dos resíduos sólidos, aumentando a produção energética. Tais investimentos são projetados nas Demonstrações Contábeis da empresa.

A operação consiste na captação de recursos de terceiros, sendo que não são considerados, para efeitos deste estudo, os encargos financeiros decorrentes, bem como qualquer forma de variação do poder aquisitivo da moeda.

Para a primeira alternativa, tendo em vista que são considerados pura e unicamente os valores dos equipamentos, a empresa estaria aumentando o seu Ativo Permanente em $15,08 \%$ (de 5.568.394,79 para 6.408.384,79) e seu Exigível à Longo Prazo em $196,96 \%$ (de $426.473,55$ para $1.266 .463,55$ ). Entretanto, deve-se levar em consideração que, com esta alternativa, a empresa estaria eliminando a grande maioria de seus resíduos sólidos de madeira e tornando-se auto-suficiente em produção energética.

Aplicação da Segunda Alternativa:

Aquisição de Máquinas para Fabricação de Subprodutos e Gastos da Queima de Resíduos Remanescentes

A segunda alternativa consiste na aquisição de máquina (juntadeira selecionadora de lâminas) que aumentará o reaproveitamento de resíduos, com a fabricação de subprodutos que possuem demanda nos mercados interno e externo, os quais lhe proporcionarão um aumento de lucratividade com a respectiva comercialização. Entretanto, esta alternativa eliminará apenas pequena quantidade dos resíduos, permanecendo as atividades de queima dos remanescentes no forno, ficando a empresa sujeita às sanções penais impostas pela legislação estadual. Desta forma, são projetados os Investimentos Ambientais nas Demonstrações Contábeis da empresa, juntamente com as Contingências Ambientais, tendo em vista que a fabricação de subprodutos eliminará apenas pequena quantidade de resíduos sólidos.

A operação também consiste na captação de recursos de terceiros, sendo que não são considerados para efeitos deste estudo, os encargos financeiros dela decorrentes, bem como qualquer forma de variação do poder aquisitivo da moeda.

Com a aplicação da segunda alternativa, tendo em vista que também são considerados unicamente os valores dos equipamentos e apenas uma autuação por infração fiscal, a empresa estaria aumentando seu Ativo Permanente em 8,74\% (de 5.568.394,79 para 6.054.954,79); seu Exigível à Longo Prazo em 260,19\% (de 426.473,55 para $1.536 .133,55)$ e reduzindo seu Patrimônio Líquido em 8,41\% (de 7.408.968,18 para $6.785 .868,18)$. Contudo, salienta-se que havendo continuidade da infração, a empresa não estaria isenta do recebimento de novas autuações, sendo que a cada ocorrência dessa, a redução detectada em seu Patrimônio Líquido estaria se multiplicando.

Aplicação da Terceira Alternativa:

Gastos Decorrentes da Decisão de Não Adquirir Novas Máquinas

A terceira alternativa consiste na decisão de não adquirir novas máquinas, mantendo a continuidade das atividades de queima de resíduos sólidos de madeira no forno, ficando a empresa sujeita às sanções penais impostas pela legislação estadual. Para tanto, são projetadas apenas as Contingências Ambientais nas Demonstrações Contábeis da empresa.

Com a aplicação da terceira alternativa, a empresa estaria aumentando seu Exigível à Longo Prazo em $146,11 \%$ (de $426.473,55$ para $1.049 .573,55$ ) e reduzindo seu Patrimônio Líquido em $8,41 \%$ (de $7.408 .968,18$ para $6.785 .868,18)$. Contudo, salienta-se, também, que havendo continuidade da infração, a empresa não estaria isenta do recebimento de novas autuações, sendo que, a cada ocorrência dessa, a redução detectada em seu Patrimônio Líquido estaria se multiplicando. 
Através das alternativas elencadas neste estudo, evidenciou-se que a empresa está exposta a impactos ambientais em seu patrimônio, conforme tabela 3 .

\section{Tabela 3 - Resumo dos Impactos Ambientais}

\begin{tabular}{c|l|c|c|c}
\hline Alternativas & Descrição & Descrição Contábil & Impacto & Causa \\
\cline { 2 - 5 } Primeira & Aquisição de máquinas para & Ativo Permanente & $15,08 \%$ & aumento \\
& redução de resíduos sólidos. & Exigível à Longo Prazo & $196,96 \%$ & aumento \\
\hline \multirow{2}{*}{ Segunda } & Aquisição de máquinas para & Ativo Permanente & $8,74 \%$ & aumento \\
& fabricação de subprodutos e gastos & Exigível à Longo Prazo & $260,19 \%$ & aumento \\
& da queima de resíduos remanescentes. & Patrimônio Líquido & $8,41 \%$ & redução \\
\hline \multirow{2}{*}{ Terceira } & Gastos decorrentes da decisão de & Exigível à Longo Prazo & $146,11 \%$ & aumento \\
& não adquirir novas máquinas. & Patrimônio Líquido & $8,41 \%$ & redução \\
\hline
\end{tabular}

Diante dos resultados obtidos, percebe-se que:

a) na aplicação da primeira alternativa, que consiste em adquirir máquinas para a redução de resíduos sólidos, a empresa estaria eliminando a grande maioria deles e tornando-se auto-suficiente em produção energética;

b) com a aplicação da segunda alternativa, que se caracteriza pela aquisição de máquinas para fabricação de subprodutos e a continuidade das atividades de queima de resíduos sólidos de madeira remanescentes no forno, a empresa teria um aumento de lucratividade com sua comercialização; entretanto, tendo em vista a necessidade de destinação final dos resíduos que não poderiam ser reaproveitados, ficaria exposta a autuações por infrações;

c) a terceira alternativa compreende os gastos decorrentes da decisão de não adquirir novas máquinas, o que ocasionaria uma redução substancial em seu patrimônio. Assim, salienta-se que havendo continuidade da infração, a empresa não estaria isenta do recebimento de novas autuações, sendo que, a cada ocorrência dessa, a redução detectada em seu Patrimônio Líquido estaria se ampliando.

Percebe-se, assim, que é relevante para a empresa a consideração dos fatores ambientais que a envolvem, tendo em vista que os mesmos estão gradativamente influenciando o desenvolvimento de suas atividades e situação patrimonial.

Neste sentido, ao optar pela realização de investimentos ambientais, torna-se adequado evidenciá-los em suas demonstrações contábeis, bem como a segregação de seus respectivos custos ambientais, de forma que os usuários externos tomem conhecimento do que vem sendo implementado nesta área, tendo em vista que causarão impactos consideráveis em suas exigibilidades.

Por outro lado, ao optar por não adquirir novas máquinas, a empresa deve considerar que está sujeita às sanções penais impostas pela legislação estadual, podendo ter uma redução substancial em sua situação patrimonial. Dessa forma, as contingências ambientais merecem atenção por parte de seus diretores, tendo em vista que as atividades do forno já estão infringindo a legislação existente e que tal fato poderá estar comprometendo sua continuidade.

\section{CONSIDERAÇÕES FINAIS}

Após a análise da empresa objeto deste estudo, detectou-se que sua maior preocupação na atualidade gira em torno do elevado índice de perda de matéria-prima durante o processo produtivo, o qual se caracteriza como um de seus principais problemas ambientais. Para tanto, a pesquisa foi direcionada no sentido de alertar para que as preocupações ambientais sejam encaradas como uma questão de sobrevivência, tendo em vista que a minimização do desperdício dos recursos naturais é relevante para a garantia de sua continuidade.

Com isso, simulou-se a realização de investimentos ambientais em seu processo produtivo, objetivando, principalmente, o reaproveitamento da grande maioria dos resíduos sólidos da madeira.

Todas as alternativas apresentadas ocasionariam um substancial aumento nas exigibilidades da empresa, ou seja, dariam origem a um passivo ambiental, de ordem preventiva, de forma que os usuários externos tomariam conhecimento do que vem sendo implementado nesta área, almejando 
um desenvolvimento econômico sustentável.

Com os resultados obtidos, detectou-se que a aquisição do equipamento completo apresentou-se como a alternativa mais adequada a ser seguida pela empresa, pois mesmo espelhando um aumento de $196,96 \%$ em suas exigibilidades, estará proporcionando benefícios econômicos, com economias de custos e incremento de fluxo de caixa e, também, benefícios estratégicos através da melhoria da imagem institucional junto aos clientes internos e externos.
Salientou-se, também, que as contingências ambientais merecem atenção por parte da empresa, em função dos impactos causados pela emissão de poluentes na atmosfera, principalmente pela queima de seus resíduos sólidos de madeira. A inobservância de tal fato poderá estar comprometendo sua continuidade, tendo em vista que pode levar a passivos ambientais vultosos. A simulação de apenas uma autuação indicou uma redução de 8,41\% em seu Patrimônio Líquido.

\section{REFERÊNCIAS BIBLIOGRÁFICAS}

BRASIL. Lei da natureza. Lei de crimes ambientais: crimes e penalidades previstas na Lei $n^{\circ} 9.605$ e no Decreto 3.179. IBAMA.

CARVALHO, L. Nelson \& RIBEIRO, Maisa de Souza. A posição das instituições financeiras frente ao problema das agressões ecológicas. Trabalho apresentado na IX Semana de Contabilidade do Banco Central do Brasil, FEA/USP. São Paulo, 0910.11.2000.

ESTADO DE MATO GROSSO. Código ambiental do Estado de Mato Grosso. Lei complementar n 38, 21 de novembro de 1995. FEMA-MT.

FIPECAFI - Fundação Instituto de Pesquisas Contábeis, Atuariais e Financeiras. Manual de contabilidade das sociedades por ações: aplicável às demais sociedades. 5 ed. São Paulo: Atlas, 2000.

HENDRIKSEN, Eldon S.; VAN BREDA, Michael F. Teoria da contabilidade. São Paulo: Atlas, 1999.

IUDÍCIBUS, Sérgio de. MARION, José Carlos. Introdução à teoria da contabilidade. 2 ed. São Paulo: Atlas, 1999.

IUDíCIBUS, Sérgio de. Teoria da contabilidade. 5 ed. São Paulo: Atlas, 1997.

MARTINS, Eliseu. Contabilidade de custos. 7 ed. São Paulo: Atlas, 2000.

MARTINS, Eliseu. DE LUCA, Márcia M. Mendes. Ecologia via contabilidade. In Revista Brasileira de Contabilidade. Ano XXIII, n 86 , março de 1994, p. 22-9.

PRICE WATERHOUSE COOPERS AUDITORES. Passivo ambiental. In Coleção Seminários CRC-SP / IBRACON: Temas contábeis em destaque. São Paulo: Atlas, 2000.

RIBEIRO, Maisa de Souza. Contabilidade e meio ambiente. 1992. Dissertação (Mestrado em Controladoria e Contabilidade). Faculdade de Economia, Administração e Contabilidade da Universidade de São Paulo, São Paulo.

Custeio das atividades de natureza ambiental. 1998. Tese (Doutorado em Controladoria e Contabilidade). Faculdade de Economia, Administração e Contabilidade da Universidade de São Paulo, São Paulo.

RIBEIRO, Maisa de Souza. LISBOA, Lázaro Plácido. Passivo ambiental. In Revista Brasileira de Contabilidade - Suplemento Especial. Brasília. Ano XXIX Nº 126 - Novembro/dezembro 2000, p. 8-19.

U. S. ENVIRONMENTAL PROTECTION AGENCY. An introduction to environmental accounting as a business management tool: key concepts and terms. 1995.

United Nations Conference on Trade and Development (Unctad). Environmental Financial Accounting and Reporting at the Corporate Level. Geneva. 1998.

www.fema.mt.gov.br. Acesso em: 08 jan. 2003.

www.sefaz.mt.gov.br. Acesso em: 14 jan. 2003.

BIBLIOGRAFIA COMPLEMENTAR

SOUZA, Ernani Lúcio Pinto de. A organização industrial do setor madeireiro no município de Sinop, Mato Grosso - uma análise da estrutura de mercado. Dissertação de Mestrado apresentada a UFPA. Belém/PA, 1999.

SOUZA, Valdiva Rossato de. Aplicação da Contabilidade

Ambiental na indústria madeireira. Dissertação de Mestrado. FEA/ USP. São Paulo, 2003.

TREVISAN AUDITORES INDEPENDENTES. Balanço social. In Coleção Seminários CRC-SP / IBRACON: Temas contábeis em destaque. São Paulo: Atlas, 2000.

MAISA DE SOUZA RIBEIRO

USP- Ribeirão Preto

Av. Bandeirantes, 3900

Ribeirão Preto - SP

$14040-900$ 